\title{
Improved amorphous/crystalline silicon interface passivation for silicon heterojunction solar cells by hot-wire atomic hydrogen during doped a-Si:H deposition
}

\author{
Zhuopeng Wu, ${ }^{\mathrm{a}, \mathrm{b}}$ Liping Zhang, ${ }^{\mathrm{a}, \mathrm{b}, *}$ Renfang Chen, ${ }^{\mathrm{a}, \mathrm{b}}$ Wenzhu Liu, ${ }^{\mathrm{c}}$ Zhenfei Li, ${ }^{\mathrm{a}, \mathrm{b}}$ Fanying Meng, ${ }^{\mathrm{a}, \mathrm{b}}$ \\ Zhengxin $\mathrm{Liu}^{\mathrm{a}, \mathrm{b}}$
}

${ }^{a}$ Research Center for New Energy Technology (RCNET), Shanghai Institute of Microsystem and Information Technology (SIMIT), Chinese Academy of Sciences (CAS), Jiading, 201800 Shanghai, People's Republic of China ${ }^{b}$ University of Chinese Academy of Sciences (UCAS), Shijingshan, 100049 Beijing, People's Republic of China ${ }^{`}$ King Abdullah University of Science and Technology (KAUST), KAUST Solar Center (KSC), Thuwai 23955-6900, Saudi Arabia

\begin{abstract}
Intrinsic/doped stacked hydrogenated amorphous silicon $(\mathrm{a}-\mathrm{Si}: \mathrm{H})$ are widely used passivation layers for amorphous/crystalline silicon (a-Si/c-Si) heterojunction solar cells. This work reports that hot wire chemical vapor deposition of doped a-Si:H can significantly modify the property of the underlying intrinsic a-Si:H (a-Si:H(i)) as well as a-Si/c-Si interface passivation, which stems from the in-diffusion of highly reactive atomic hydrogen. Fourier transform infrared spectroscopy, spectroscopic ellipsometry and Raman analyses indicate that the underlying a-Si:H(i) films become more compact and less defected as a result of network reconstruction during doped a-Si:H capping. After this reconstruction, underdense a-Si:H(i) films obtained superior passivation quality than widely used dense layers, despite the inferior quality in the initial state. Effective minority carrier lifetime of c-Si passivated by underdense a-Si:H(i) was $19.9 \mathrm{~ms}$, much higher than $15.2 \mathrm{~ms}$ in the case of using dense a-Si:H(i). The porous structure of underdense a-Si:H(i) facilitates hydrogen diffusion towards a-Si/cSi interface and hence a rapid reduction of interface defect densities occurs, accounting for the better passivation quality. SHJ solar cells $\left(160 \mu \mathrm{m}, 156 \times 156 \mathrm{~mm}^{2}\right)$ with industry-compatible process were fabricated, yielding the efficiency up to $23.0 \%$ with high $V_{\text {oc }}$ values of $741 \mathrm{mV}$.
\end{abstract}




\section{Keywords}

Surface passivation; Hydrogenated amorphous silicon; Amorphous/crystalline silicon heterojunction solar cells; Hot wire chemical vapor deposition

*Corresponding author

Email address: zlp_wan@mail.sim.ac.cn

\section{Introduction}

Among high-efficiency photovoltaic devices, amorphous/crystalline silicon heterojunction (SHJ) solar cells stand out due to their high performance and potential for low production cost [1]. A record conversion efficiency of $24.7 \%$ with an open circuit voltage $\left(V_{\mathrm{oc}}\right)$ of $750 \mathrm{mV}$ was reported [2]. The doping of the hydrogenated amorphous silicon $(\mathrm{a}-\mathrm{Si}: \mathrm{H})$ to form efficient $\mathrm{p}-\mathrm{n}$ junction and back surface field with a high built-in voltage leads to high defect density in the a-Si:H bulk and at the a-Si/c-Si interface [3]. Therefore, a thin intrinsic passivation layer is inserted between the doped layers and wafer to reduce the defect density at the a-Si/c-Si interface $\left(D_{\mathrm{it}}\right)$ and thus restrain the surface carrier recombination, improving the $V_{\text {oc }}$ of SHJ solar cells [4]. The typical 5-10 nm thick a-Si:H layers are usually prepared by chemical vapor deposition (CVD), either by plasma-enhanced CVD (PECVD) or by hot-wire CVD (HWCVD).

Post hydrogen plasma treatments in PECVD have been extensively applied in band gap engineering [5, 6], facilitating network crystallization [7], promoting amorphous-to-microcrystalline transition and improving the hydrogenation of wafer/film interface [8], via hydrogen in-diffusion from the kinetic plasma environment and further relaxation of the a-Si:H films. In contrast to the dissociation of $\mathrm{H}_{2}$ by collisions with energetic electrons in PECVD, $\mathrm{H}_{2}$ is efficiently decomposed into atomic $\mathrm{H}$ by catalytic cracking reaction with the heated filament in HWCVD [9]. Coincidentally, a calculated diffusion coefficient for hot-wire atomic hydrogen agrees well with the value for diffusion from hydrogen plasma [10], which implies the highly-reactive nature of hot-wire atomic $\mathrm{H}$. These $\mathrm{H}$ atoms can penetrate into the as-deposited poly- $\mathrm{Si}_{1-\mathrm{x}} \mathrm{Ge}_{\mathrm{x}}$ films and terminate the unsaturated dangling bonds, 
with an effective post-hydrogenation depth up to $250 \mathrm{~nm}$ [11]. Regarding this, the ultrathin (5-10 nm) intrinsic a-Si:H film for SHJ device must be susceptible to the exposure to hot-wire atomic hydrogen. As for doped a-Si:H deposition for $\mathrm{SHJ}$ device, a high hydrogen dilution $\left(R_{\mathrm{H}}\right)$ is commonly employed to enhance the crystallinity which benefits the doping efficiency [12]. This high $R_{\mathrm{H}}$ indeed leads to plentiful atomic $\mathrm{H}$ in the chamber, which may influence the underlying intrinsic films, a-Si/c-Si interface property and hence the passivation quality. The effect of inherent atomic $\mathrm{H}$ during the doped layer process in HWCVD has to be studied.

In this paper, we investigated the passivation effect induced by hydrogen penetration during subsequent deposition of $\mathrm{n}$-type a-Si:H $\left(\mathrm{a}-\mathrm{Si}: \mathrm{H}\left(\mathrm{n}^{+}\right)\right)$in HWCVD. After a-Si:H( $\left(\mathrm{n}^{+}\right)$capping, underdense a-Si:H(i) film was observed to provide better passivation quality compared with widely used dense aSi:H(i), despite the inferior passivation in the initial state. To clarify the improvement mechanism, a nanometer-accurate chemical etching method was carried out to uncover the microstructure evolution of underlying intrinsic films caused by the in-diffusion of highly-reactive atomic $\mathrm{H}$ during a-Si:H( $\left.\mathrm{n}^{+}\right)$ capping. Finally, SHJ solar cells were optimized and a conversion efficiency of $23.0 \%$ was achieved. Such underdense a-Si:H(i) has great potential as an excellent passivation layer alternative for high performance SHJ solar cells.

\section{Materials and methods}

A-Si:H films were deposited on Czochralski phosphorus-doped c-Si (100) wafers (thickness, 160 $\mu \mathrm{m}$; resistivity, 1-6 $\Omega \mathrm{cm}$ ) in a multi-chamber HWCVD. The filaments for a-Si:H deposition are alloys which is composed of tungsten and tantalum [13]. Prior to a-Si deposition, the wafers were textured with potassium hydroxide, followed by the standard RCA cleaning process, then dipped in $2 \%$ diluted hydrofluoric acid (HF) for $1 \mathrm{~min}$ to remove the native oxide. A-Si:H(i) layers were deposited with pressure of $1.0 \mathrm{~Pa}$, filament temperature $\left(\mathrm{T}_{\text {fila }}\right)$ of $1700{ }^{\circ} \mathrm{C}$, silane flow rates of $60 \mathrm{sccm}$ without hydrogen dilution. For underdense a-Si:H(i), the substrate temperature $\left(\mathrm{T}_{\mathrm{s}}\right)$ was set at $120{ }^{\circ} \mathrm{C}$, while dense a-Si:H(i) were fabricated at $\mathrm{T}_{\mathrm{s}}$ of $160^{\circ} \mathrm{C}$ (hereafter referred as $\mathrm{I}_{120}$ and $\mathrm{I}_{160}$ respectively). A$\mathrm{Si}: \mathrm{H}\left(\mathrm{n}^{+}\right)$film was deposited with $\mathrm{T}_{\mathrm{s}}$ of $130^{\circ} \mathrm{C}$, $\mathrm{T}_{\text {fila }}$ of $2000^{\circ} \mathrm{C}$ and $R_{\mathrm{H}}$ of 4 . In symmetrical $\mathrm{i} / \mathrm{n}^{+}$structure passivation as shown in Fig. 2, the thickness of a-Si:H(i) was fixed at $10 \mathrm{~nm}$ and that of a-Si:H(n $\left(\mathrm{n}^{+}\right)\left(\mathrm{d}_{\mathrm{n}^{+}}\right)$ varied, 4, 6, 8, $10 \mathrm{~nm}$ by adjusting deposition time. The lifetime of minority carrier $\left(\tau_{\mathrm{eff}}\right)$ was measured 
with micro-wave photo-conductance decay ( $\mu$-PCD) method (Sinton Consulting WCT-120 system, operated at the transient analysis mode and evaluated at a minority carrier injection density of $1.0 \times$ $\left.10^{15} \mathrm{~cm}^{-3}\right)$.

To probe the structural evolution of the underlying intrinsic films after a- $\mathrm{Si}: \mathrm{H}\left(\mathrm{n}^{+}\right)$deposition, we used a simple method of chemical etching, as illustrated in Fig. $1.10 \mathrm{~nm} \mathrm{i,} 6 \mathrm{~nm} \mathrm{n}+10 \mathrm{~nm}$ i and $10 \mathrm{~nm}$ $\mathrm{n}^{+} / 10 \mathrm{~nm}$ i for both $\mathrm{I}_{120}$ and $\mathrm{I}_{160}$ were deposited on single polished c-Si wafers (float-zone; thickness, $525 \mu \mathrm{m}$; resistivity, $3000 \Omega \mathrm{cm}$ ). The c-Si wafers were dipped in $2 \% \mathrm{HF}$ to remove native oxide prior to a-Si:H deposition. After then, a-Si:H(n $\left.\mathrm{n}^{+}\right)$overlayers were etched away in a mixed solution of $30 \%$ hydrogen peroxide $\left(\mathrm{H}_{2} \mathrm{O}_{2}\right): 50 \% \mathrm{HF}(4: 1)$ with an average etching rate of $\sim 0.5 \mathrm{~nm} / \mathrm{min}$. More specifically, uppermost amorphous silicon is oxidized by $\mathrm{H}_{2} \mathrm{O}_{2}$ and the pre-formed oxide film is immediately etched away by HF. With spectroscopic ellipsometry, we verified the accurate etching to the $\mathrm{i} / \mathrm{n}^{+}$interface by controlling etching time and no a-Si:H(n+) traces remained on the sample (the remained a-Si:H thickness after etching is $10 \mathrm{~nm}$, exactly that of a-Si:H(i) film). The optical parameters of a-Si:H films were characterized by Spectroscopic Ellipsometry (SE; J. A. Woollam, M-2000XI) fitted with Tauc-Lorentz model [14]. The Si-Hx bonding was characterized by Fourier Transform Infrared Spectroscopy (FTIR; Perkin Elmer, Spectrum100). For the FTIR characterization, a piece of the single polished $\mathrm{Si}$ wafer was dipped in $2 \% \mathrm{HF}$ for $1 \mathrm{~min}$ to remove the surface native oxide, followed by a scan in the background mode. A-Si:H films were then characterized with FTIR in the sample mode. The complete transmittance spectra in the region $\omega=450-4000 \mathrm{~cm}^{-1}$ (see Fig. S1) were collected until $\mathrm{CO}_{2}$ peak at $2350 \mathrm{~cm}^{-1}$ disappeared after $\mathrm{N}_{2}$ blowing for 40 minutes to drain the air in the equipment. After then, the $\mathrm{H}$ bonding configuration was quantified by analyzing the stretching modes of Si-Hx bonding [15]. Raman spectra were recorded using a $325 \mathrm{~nm}$ He-Cd laser excitation (Jovin Yvon Labram 800002). For Raman characterization, thickness of a-Si:H(i) films were 40 nm by adjusting deposition time to absorb the laser completely so that the signal from c-Si substrate can be avoided. Cross-section images for a-Si/c-Si interface were acquired by high-resolution transmission electron microscopy (HR-TEM; Tecnai G2 F20 S-Twin), at a voltage of $200 \mathrm{kV}$. 


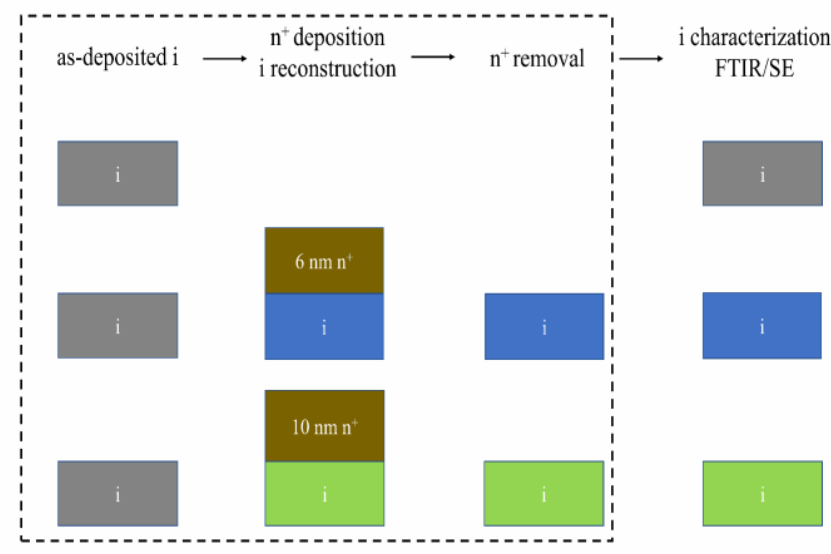

FIG. 1. Schematic illustration of the characterization process of the underlying intrinsic a-Si:H by a simple chemical etching method.

\section{Results and discussion}

\subsection{Passivation quality in i structure}

Table 1 shows $\mathrm{H}$ incorporation, the maximum imaginary part $\left(\mathcal{E}_{\mathrm{i}-\mathrm{max}}\right)$ of the dielectric function of as-deposited underdense/dense intrinsic films and the passivation quality in symmetrical a-Si:H(i)/c$\mathrm{Si}(\mathrm{n}) / \mathrm{a}-\mathrm{Si}: \mathrm{H}(\mathrm{i})$ structure (i structure). Generally, low stretching mode (LSM, at $1980-2020 \mathrm{~cm}^{-1}$ ) is assigned to isolated hydrogen in dense network structure, while high stretching mode (HSM, at 2070$2100 \mathrm{~cm}^{-1}$ ) mainly represents clustered hydrogen at the internal surfaces of microvoids, corresponding to the poor film quality [15]. The microstructure factor $R$ was calculated from the following equation [16]:

$$
R=C_{\mathrm{HSM}} /\left(C_{\mathrm{HSM}}+C_{\mathrm{LSM}}\right)
$$

Obviously, higher value of $R$ represents higher porosity of a-Si:H structure. As Table 1 shows, HSM hydrogen content $\left(C_{\mathrm{HSM}}\right)$ predominates in hydrogen distribution for $\mathrm{I}_{120}$ and correspondingly a high value of $R$ was obtained, indicating a high degree of porosity associated with large amounts of strained $\mathrm{Si}-\mathrm{Si}$ bonds and dangling bonds. This is due to a limited diffusivity of film-growth precursors and inadequate network reconstruction at low substrate temperature [17]. Raising $\mathrm{T}_{\mathrm{s}}$ to $160{ }^{\circ} \mathrm{C}$ significantly reduces $C_{\mathrm{HSM}}$ while enlarges LSM hydrogen content $\left(C_{\mathrm{LSM}}\right)$, resulting in a significant reduction of $R$ from 0.65 to 0.25 . Meanwhile, hydrogen elimination occurs more readily due to adequate thermal hydrogen desorption [18], which accounts for the lower total hydrogen content $\left(C_{\text {total }}\right)$ for $\mathrm{I}_{160}$. In 
addition, a pronounced increase in $\varepsilon_{\text {i-max }}$ from 21.1 to 24.7 also demonstrates a larger mass density of $I_{160}$ [19]. To summarize, $I_{160}$ is more compact and less defective than $I_{120}$. Consequently, underdense a$\mathrm{Si}: \mathrm{H}(\mathrm{i})$ provided inferior passivation as evidenced by a very low $\tau_{\text {eff }}$ of $164 \mu \mathrm{s}$, which is almost oneeighth that of dense a-Si:H(i).

TABLE 1 . Film properties and the passivation quality of $10 \mathrm{~nm}$ intrinsic layers in the as-deposited state.

\begin{tabular}{ccccccc}
\hline & $C_{\mathrm{HSM}}(\%)$ & $C_{\mathrm{LSM}}(\%)$ & $C_{\text {total }}(\%)$ & $R$ & $\mathcal{E}_{\text {i-max }}$ & $\tau_{\mathrm{eff}}(\mu \mathrm{s})$ \\
\hline $\mathrm{I}_{120}$ & 9.0 & 4.8 & 13.8 & 0.65 & 21.1 & 164 \\
$\mathrm{I}_{160}$ & 3.2 & 9.5 & 12.7 & 0.25 & 24.7 & 1327 \\
\hline
\end{tabular}

3.2 Passivation quality in $\mathrm{i} / \mathrm{n}^{+}$structure

Contrary to the inferior performance in i structure passivation, underdense a-Si:H(i) performs better after a-Si:H(n $\left(\mathrm{n}^{+}\right)$capping. Figure 2 plots the $\tau_{\text {eff }}$ of c-Si symmetrically passivated by $\mathrm{i} / \mathrm{n}^{+}$stack layer versus increscent a-Si:H( $\left.\mathrm{n}^{+}\right)$thickness. By increasing the thickness of a-Si:H(n+) layer to $10 \mathrm{~nm}$, the $\tau_{\text {eff }}$ of c-Si passivated by $\mathrm{I}_{120}$ increases significantly from $0.164 \mathrm{~ms}$ to $19.9 \mathrm{~ms}$, which is much higher than $15.2 \mathrm{~ms}$ in the case of using dense $\mathrm{I}_{160}$. As Fig. 2 shows, in either case of intrinsic layers, $\tau_{\text {eff }}$ benefits substantially from thickening doped a-Si:H layers. Theoretically, a-Si:H( $\left.\mathrm{n}^{+}\right)$layer induces a downward band bending inside the wafer, repelling the holes and hence reducing the electron/hole recombination at the a-Si/c-Si interface (field-effect passivation) [20]. Such thickness dependence of $\tau_{\text {eff }}$ is mainly due to the improved surface field effects which markedly gains with doped layer thickness. Note that since the field-effect passivation provided by doped layer is equal at each a-Si:H(n $\left.\mathrm{n}^{+}\right)$ thickness in Fig. 2, the $\tau_{\text {eff }}$ difference between $\mathrm{I}_{120}$ and $\mathrm{I}_{160}$ must therefore derive from different $D_{\text {it }}$ values. From the comparison, two distinct regions are identified. Initially $\left(\mathrm{d}_{\mathrm{n}^{+}}<6 \mathrm{~nm}\right)$, the higher $\tau_{\text {eff }}$ of $\mathrm{I}_{160}$ clearly indicates a lower $D_{\text {it }}$ for dense passivation layer, consistent with $\tau_{\text {eff }}$ result in i passivation.

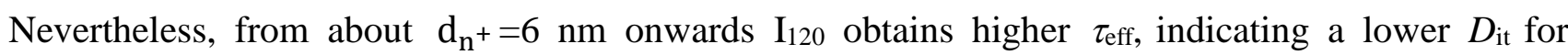
underdense intrinsic films after a-Si:H(n+) deposition despite the defective a-Si/c-Si interface in the initial state. This discrepancy indicates that the a-Si(i)/c-Si interface defect density is reduced during a-Si:H( $\left.\mathrm{n}^{+}\right)$deposition. As the physical mechanism responsible for Dit reduction is the chemical passivation of Si- dangling bonds by hydrogen [21], it's inferred that subsequent a-Si:H( $\left.\mathrm{n}^{+}\right)$deposition 
induced rehydrogenation at the a-Si(i)/c-Si interface. This is the evidence of atomic hydrogen diffusion into the intrinsic films from the H-rich environment during a-Si:H( $\left.\mathrm{n}^{+}\right)$capping. As a consequence of longer periods of exposure to the atomic hydrogen by fabricating thicker a-Si:H( $\left.\mathrm{n}^{+}\right)$, a higher hydrogenation level at the interface is obtained for underdense $\mathrm{I}_{120}$ compared with dense $\mathrm{I}_{160}$, leading to better passivation performance. This demonstrates that the porous structure of underdense a-Si:H(i) facilitates hydrogen diffusion towards a-Si/c-Si interface and hence a more rapid reduction of $D_{\text {it }}$ occurs.

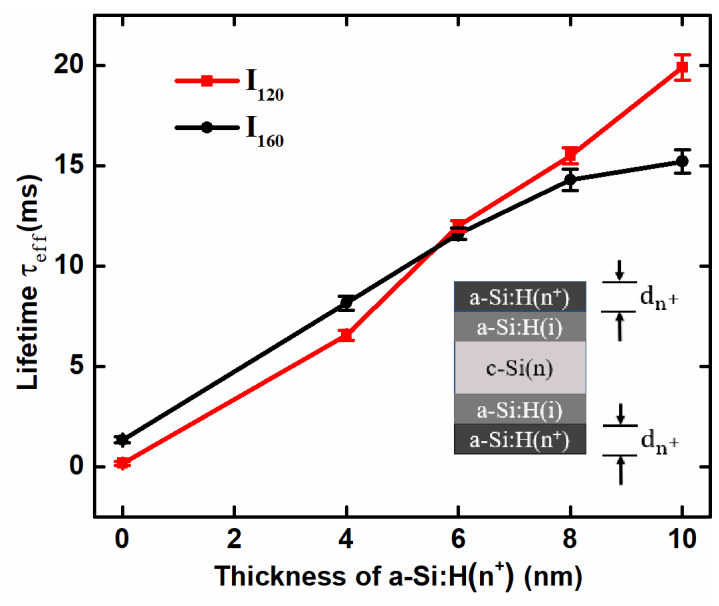

FIG. 2. $\tau_{\text {eff }}(\mathrm{ms})$ values of c-Si passivated by $\mathrm{i} / \mathrm{n}^{+}$stack layer versus a-Si:H( $\left.\mathrm{n}^{+}\right)$thickness $\left(\mathrm{d}_{\mathrm{n}^{+}}\right)$. Thickness of $\mathrm{i}$ was $10 \mathrm{~nm}$ and $\mathrm{d}_{\mathrm{n}^{+}}$varied, 4, 6, 8, $10 \mathrm{~nm}$. For reference, values for i structure (depicted in Table I) is given as well (corresponding to $\mathrm{d}_{\mathrm{n}^{+}}=0 \mathrm{~nm}$ ).

\subsection{Microstructure reconstruction of a-Si:H(i) during a-Si:H(n $\left.{ }^{+}\right)$capping}

As Fig. 3 shows, subsequent $\mathrm{n}^{+}$deposition strongly affects the silicon-hydrogen bonding of the intrinsic films beneath. For both intrinsic films, the intensity of HSM markedly drops with increasing $\mathrm{d}_{\mathrm{n}}+$ while LSM absorbance increases, compared with the as-deposited state. On the one hand, large amounts of kinetic hydrogen atoms generated by dissociation of $\mathrm{H}_{2}$ easily diffuse into a-Si:H(i) bulk and terminate the dangling bonds in the vacancies, which leads to the augment in $C_{\mathrm{LSM}}$. On the other hand, as the $\mathrm{H}$ atoms move through the a-Si:H matrix, they either break or perturb strained $\mathrm{Si}-\mathrm{Si}$ bonds [7]. Subsequent relaxation of these strained bonds results in the transformation of the film's structure and decreases the number of microvoids, as indicated by the decline of HSM absorbance. Consequently, the microstructure factor $R$ decreases monotonically, i.e. from 0.25 to 0.06 for $\mathrm{I}_{160}$ as illustrated in Fig. 
3(a)-(c) and from 0.65 to 0.44 for $\mathrm{I}_{120}$ in Fig. 3(d)-(f) (the error in determining $R$ is shown in Fig. S2). Additionally, the imaginary part of dielectric function $\left(\varepsilon_{\mathrm{i}}\right)$ of a-Si:H(i) also increases as the arrow indicates in Fig. 4(a). This indicates the increscent mass density of a-Si:H(i) caused by H incorporation. Fig. 4(b) shows the Raman spectra of a-Si:H(i) films in the as-deposited state and after $10 \mathrm{~nm} \mathrm{n}^{+}$ depo\&etch. The Raman signal due to the transverse optical mode was deconvoluted into three components: $I_{\mathrm{a}}$ (approx. $480 \mathrm{~cm}^{-1}$, amorphous phase), $I_{\mathrm{m}}$ (approx. $510 \mathrm{~cm}^{-1}$, crystalline phase with a grain size smaller than $10 \mathrm{~nm}$ ) and $I_{\mathrm{c}}$ (approx. $520 \mathrm{~cm}^{-1}$, crystalline phase with a grain size larger than $10 \mathrm{~nm}$ ) [22]. On the one hand, as shown in Fig. 4(b), the single peak centered around $480 \mathrm{~cm}^{-1}$ suggests that the a-Si:H(i) films are purely amorphous without crystallization. On the other hand, the slight increase of the peak frequency after $10 \mathrm{~nm}$ a-Si:H(n+) depo\&etch for both $\mathrm{I}_{120}$ and $\mathrm{I}_{160}$ indicates a decrease in the network disorder [23] as well as a reduced lattice expansion [24]. This demonstrates that the underlying a-Si:H(i) becomes more ordered and compact as a result of network reconstruction caused by a mass of kinetic hydrogen during a-Si: $\mathrm{H}\left(\mathrm{n}^{+}\right)$capping.
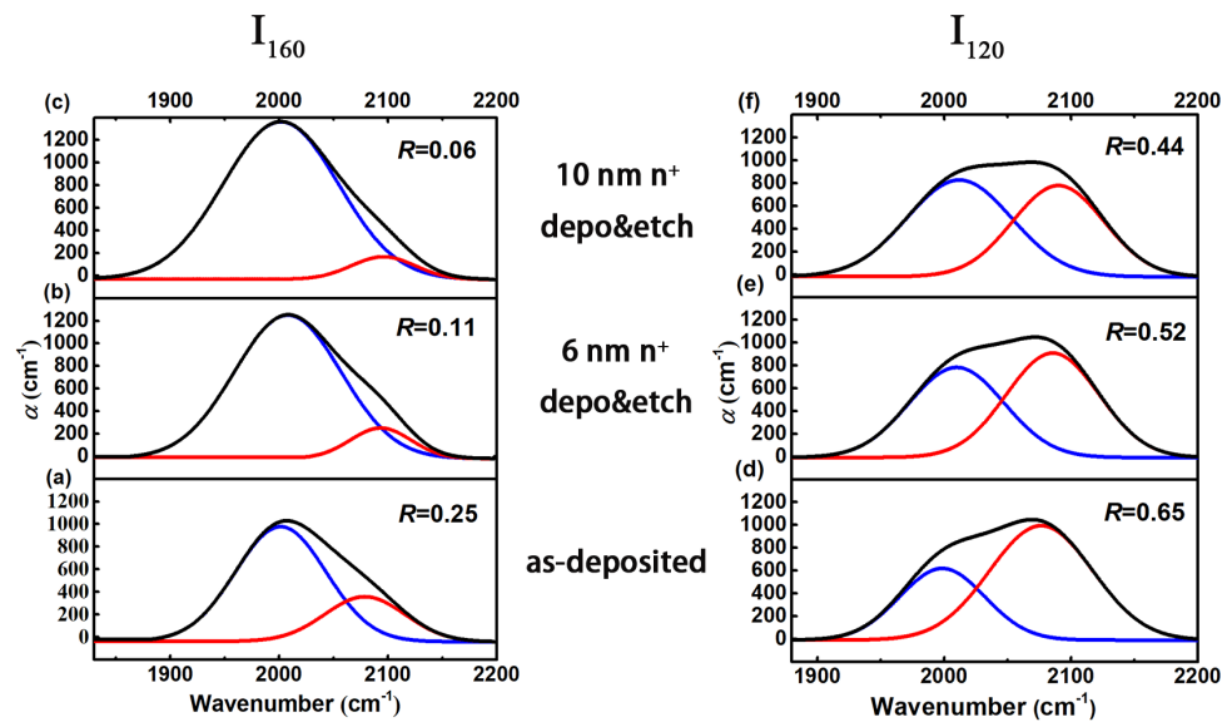

FIG. 3. FTIR spectra evolutions of the 10-nm-thick intrinsic layers, deconvoluted into the LSM and HSM peaks with calculated microstructure factor $R$ shown. (a) as-deposited (b) $6 \mathrm{~nm} \mathrm{n}^{+}$deposition and etching (depo\&etch) (c) $10 \mathrm{~nm} \mathrm{n}$ depo\&etch for $\mathrm{I}_{160}$ and (d) as-deposited (e) $6 \mathrm{~nm} \mathrm{n}^{+}$depo\&etch (f) $10 \mathrm{~nm} \mathrm{n}^{+}$depo\&etch for $\mathrm{I}_{120}$. 

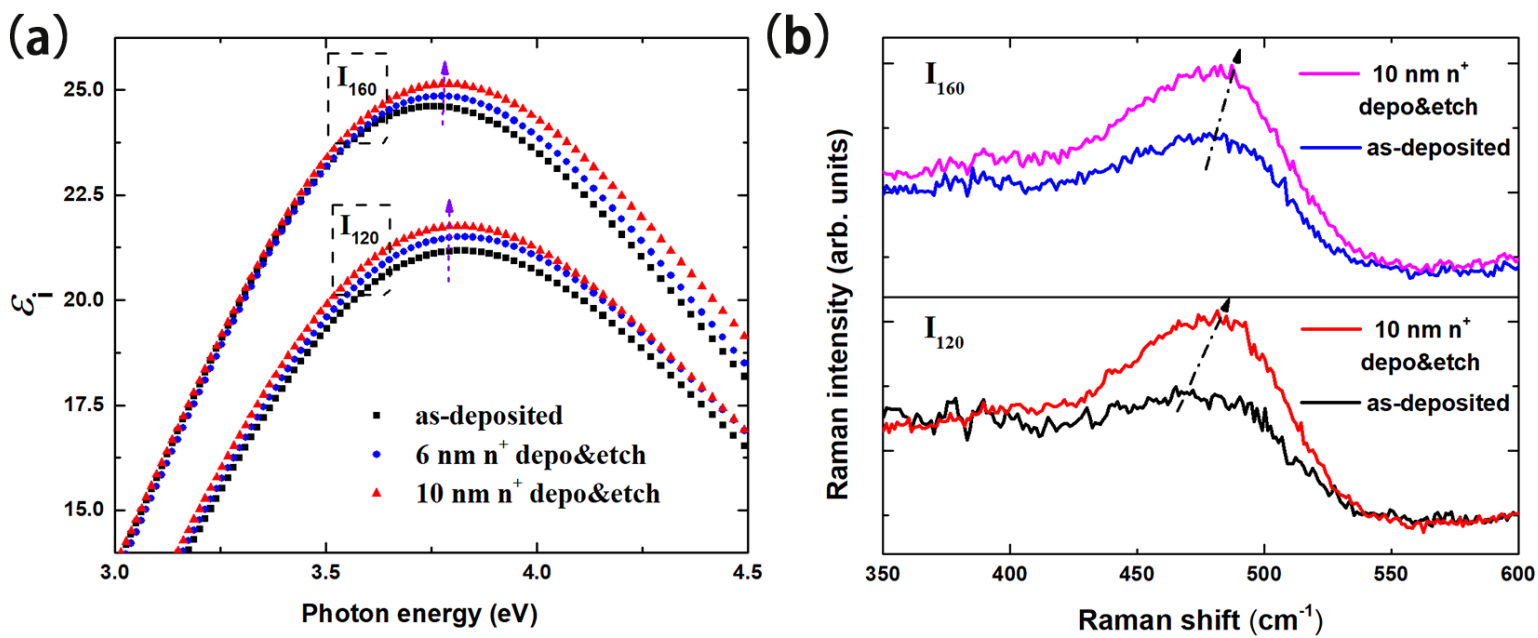

FIG. 4. (a) The imaginary part of dielectric function $\left(\mathcal{E}_{\mathrm{i}}\right)$ evolution and (b) Raman spectra evolution of a-Si:H(i) during a$\mathrm{Si}: \mathrm{H}\left(\mathrm{n}^{+}\right)$deposition.

Fig. 5(a) and Fig. 5(c) exhibits the cross-sectional HR-TEM images of a-Si:H(i)/c-Si for I120 and $\mathrm{I}_{160 .}$ Pure silane deposition results in a typically amorphous bulk of a-Si:H(i), which is consistent with the single Raman peak centered around $480 \mathrm{~cm}^{-1}$ in Fig. 4(b). Meanwhile, a smooth a-Si(i)/c-Si interface without epitaxy was obtained, which is a key factor to yield outstanding surface passivation [25]. After $10 \mathrm{~nm}$ a-Si:H(n $\left.{ }^{+}\right)$deposition, the a-Si(i)/c-Si interface remains smooth for both $\mathrm{I}_{120}$ and $\mathrm{I}_{160}$ as displayed in Fig. 5(b) and Fig. 5(d). Additionally, no crystallite was observed in the highlydisordered a-Si:H(i) network, corresponding to the lack of $I_{\mathrm{c}}$ and $I_{\mathrm{m}}$ Raman peak after $10 \mathrm{~nm}$ a-Si:H(n $\left(\mathrm{n}^{+}\right)$ depo\&etch in Fig. 4(b). To conclude, FTIR, SE, Raman and HR-TEM results demonstrate that a-Si:H(i) bulk property was enhanced and a smooth a-Si/c-Si interface was maintained during the kinetic hydrogen penetration during a-Si:H(n+) capping. The enhanced a-Si:H(i) property reduces the carrier recombination in the bulk, partially contributing to the $\tau_{\text {eff }}$ improvement in Fig. 2 .

It is noteworthy that the bulk property of $\mathrm{I}_{120}$ remains inferior than $\mathrm{I}_{160}$ even after reconstruction during $10 \mathrm{~nm}$ a-Si:H(n $\left.{ }^{+}\right)$deposition as revealed by the greater $R(0.44$ versus 0.06$)$ displayed in Fig. 3(f) and Fig. 3(c) and the smaller $\varepsilon_{\mathrm{i}}$ in Fig. 4(a), which seems contradictory to the higher $\tau_{\text {eff }}(19.9 \mathrm{~ms}$ vs. $15.2 \mathrm{~ms}$ ) as shown in Fig. 2. The poorer bulk property yet higher $\tau_{\text {eff }}$ for underdense films demonstrates that a-Si/c-Si interface quality rather than a-Si:H bulk property determines c-Si surface passivation quality. Such underdense a-Si:H(i) capped by a-Si:H(n+ $\left.{ }^{+}\right)$has the potential to enhance the $V_{\text {oc }}$ of SHJ solar cell thanks to the higher a-Si/c-Si interface hydrogenation level. 
(a)
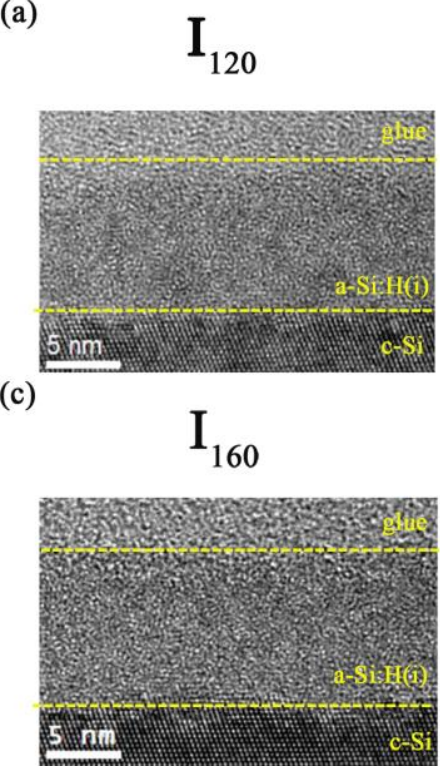

(b)

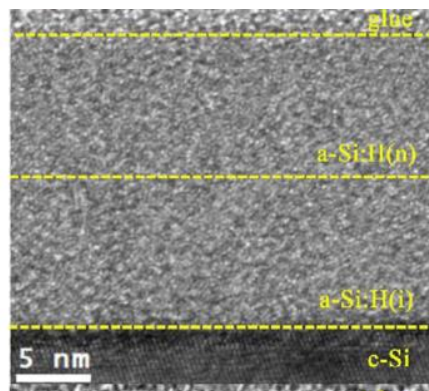

(d)

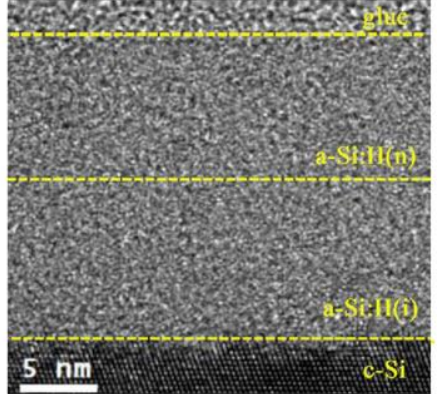

FIG. 5. HRTEM image of c-Si coated by (a) $10 \mathrm{~nm} \mathrm{I}_{120}$, (b) $10 \mathrm{~nm} \mathrm{I}_{120} / 10 \mathrm{~nm} \mathrm{n}^{+}$, (c) $10 \mathrm{~nm} \mathrm{I}_{160}$ and (d) $10 \mathrm{~nm} \mathrm{I}_{160} / 10 \mathrm{~nm}$ $\mathrm{n}^{+}$.

\subsection{Cell performance}

Based on the discussion above, $160 \mu \mathrm{m}$ SHJ rear emitter solar cells $\left(156 \times 156 \mathrm{~mm}^{2}\right)$ were fabricated with industry-compatible process, details about the cell structures and process can be found in our previous paper [26]. The dependence of current-voltage parameters of SHJ solar cells versus a$\mathrm{Si}: \mathrm{H}\left(\mathrm{n}^{+}\right)$thickness is illustrated in Fig. 6, measured at standard condition of AM1.5 and $25^{\circ} \mathrm{C}$. As Fig. 6(a) shows, $V_{\text {oc }}$ sustainably increases with $\mathrm{d}_{\mathrm{n}^{+}}$, consistent with $\tau_{\text {eff }}$ results as shown in Fig. 2 . The higher $V_{\text {oc }}$ of cell passivated by $\mathrm{I}_{120}$ compared with $\mathrm{I}_{160}$ further confirms the lower $D_{\text {it }}$ and better passivation due to more adequate rehydrogenation at the a-Si/c-Si interface [27], as a result of the indiffusion of hot-wire atomic hydrogen. From the viewpoint of c-Si surface passivation, thicker a$\mathrm{Si}: \mathrm{H}\left(\mathrm{n}^{+}\right)$layer is a positive factor for SHJ solar cell performance but this in turn leads to more parasitic absorption [28] and thus lower $J_{\text {sc }}$ as shown in Fig. 6(b). Nevertheless, it is interesting to note the improvement in $J_{\mathrm{sc}}$ using underdense a-Si:H(i) as front-side passivation layers thanks to the lower parasitic optical loss [29], as implied by lower $\varepsilon_{\mathrm{i}-\max }$ and higher $C_{\mathrm{H}}$ in Table 1. Therefore, such underdense intrinsic passivation layer provides an approach towards higher $J_{\mathrm{sc}}$ of SHJ cells without deteriorating electronic passivation quality by HWCVD. Although the loose network of $\mathrm{I}_{120}$ results in higher series resistance as revealed by the lower $F F$ in Fig. 6(c), the loss in $F F$ can be offset by the 
gain in $V_{\mathrm{oc}}$ and $J_{\mathrm{sc}}$. At an optimal a-Si:H(n $\left.{ }^{+}\right)$thickness of $8 \mathrm{~nm}$, a high conversion efficiency up to $23.0 \%$ with $V_{\text {oc }}$ of $741 \mathrm{mV}$ was achieved.
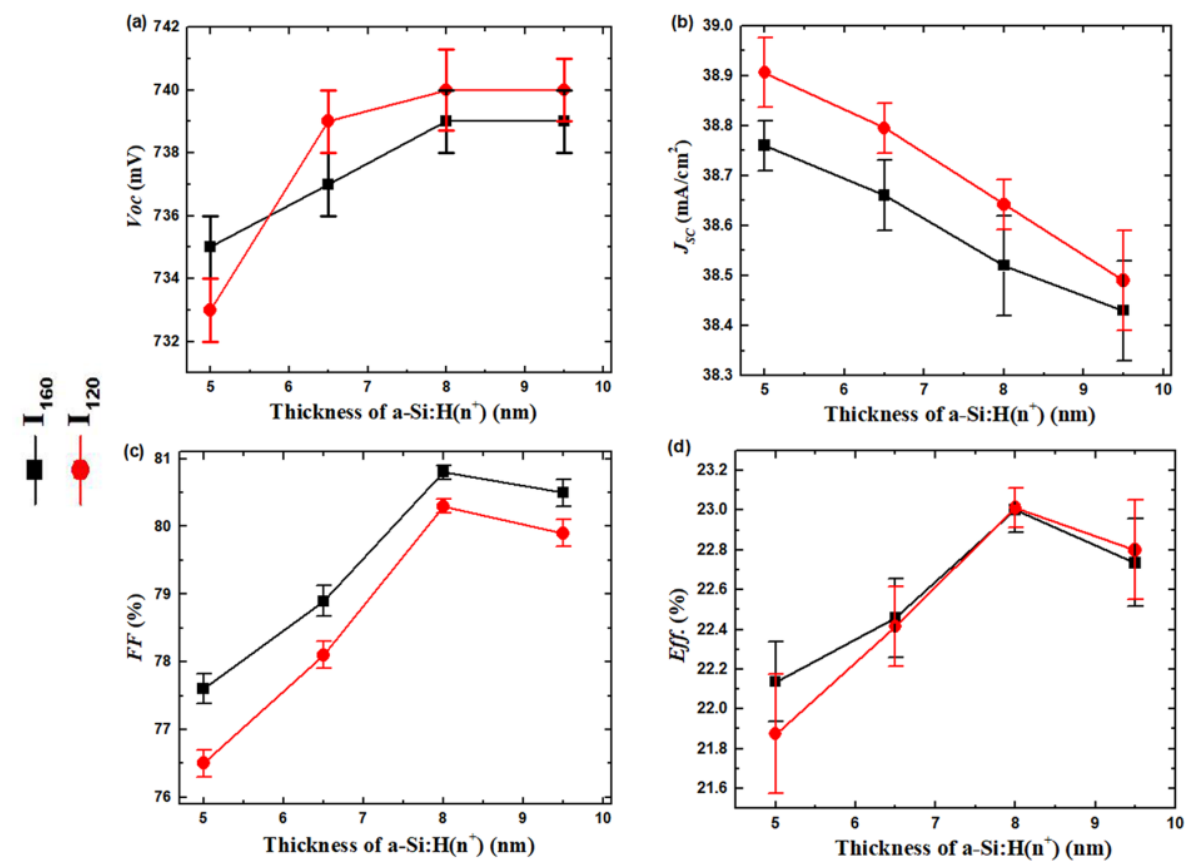

FIG. 6. (a) $V_{\mathrm{oc}}$, (b) $J_{\text {sc }}$, (c) $F F$, and (d) Eff. of SHJ solar cells versus a-Si:H(n+) thickness, squares for dense $\mathrm{I}_{160}$ and circles for underdense $\mathrm{I}_{120}$.

\section{Conclusions}

To summarize, hot-wire atomic hydrogen during subsequent n-type a-Si:H deposition can significantly modify the microstructure and improve the bulk property of the underlying intrinsic passivation layers, experimentally investigated by a nanometer-accurate chemical etching method. Additionally, c-Si surface passivation quality was improved as a result of kinetic hydrogen in-diffusion towards the a-Si/c-Si interface. Compared with widely used dense a-Si:H(i), a higher hydrogenation level at the a-Si/c-Si interface was obtained for underdense a-Si:H(i) as the porous structure facilitates hydrogen diffusion. Consequently, higher $\tau_{\text {eff }}$ and higher $V_{\mathrm{oc}}$ of SHJ solar cells was obtained, demonstrating that such underdense a-Si:H(i) capped by doped a-Si:H has great potential as an excellent passivation layer alternative for high performance SHJ solar cells. Our results revealed that doping layer deposition in HWCVD not only introduces field effect but also may improve the chemical passivation quality of the underlying intrinsic films. This concept is promising for guiding the design 
of intrinsic/doped a-Si:H stack layers in pursuit of high efficiency of SHJ solar cells.

\section{Acknowledgements}

The authors gratefully acknowledge ULVAC for their equipment support of HWCVD deposition system. This work was supported by projects of the Strategic Priority Research Program and the Joint Fund of Chinese Academy of Sciences (XDA17020403, 6141A01141604), and a project of Shanghai Municipal Science and Technology Committee (17DZ1201100).

\section{References}

[1] S. De Wolf, A. Descoeudres, Z. C. Holman, C. Ballif, High-efficiency silicon heterojunction solar cells: A review, Green 2 (2012) 7-24. https://doi.org/10.1515/green-2011-0018.

[2] M. Taguchi, A. Yano, S. Tohoda, K. Matsuyama, Y. Nakamura, T. Nishiwaki, K. Fujita, E. Maruyama, 24.7\% record efficiency HIT solar cell on thin silicon wafer, IEEE J. Photovoltaics 4 (2014) 96-99. 10.1109/JPHOTOV.2013.2282737.

[3] H. Dersch, J. Stuke, J. Beichler, Electron Spin Resonance of Doped Glow- Discharge Amorphous Silicon, Physica status solidi (b) 105 (1981) 265-274. https://doi.org/10.1002/pssb.2221050129.

[4] M. Tanaka, M. Taguchi, T. Matsuyama, T. Sawada, S. Tsuda, S. Nakano, H. Hanafusa1 and Y. Kuwano, Development of New a-Si/c-Si Heterojunction Solar Cells: ACJ-HIT (Artificially Constructed JunctionHeterojunction with Intrinsic Thin-Layer), Japanese J. Appl. Phys. 31(1992) 3518-3522. http://iopscience.iop.org/1347-4065/31/11R/3518.

[5] M. Mews, T. F. Schulze, N. Mingirulli, L. Korte, Hydrogen plasma treatments for passivation of amorphouscrystalline silicon-heterojunctions on surfaces promoting epitaxy, Appl. Phys. Lett. 102 (2013) 122106. https://doi.org/10.1063/1.4798292.

[6] Yingnan Guo, Thiam Min Brian Ong, I. Levchenko, ShuyanXu, Inductively and capacitively coupled plasmas at interface: A comparative study towards highly efficient amorphous-crystalline Si solar cells, Appl. Sur. Sci. 427 (2018) 486-493. https://doi.org/10.1016/j.apsusc.2017.08.125.

[7] S. Sriraman, S. Agarwal, E. S. Aydil, D. Maroudas, Mechanism of hydrogen-induced crystallization of amorphous silicon, Nature 418 (2002) 62. https://www.nature.com/articles/nature00866.

[8] A. Descoeudres, L. Barraud, S. De Wolf, B. Strahm, D. Lachenal, C. Guérin, Z. C. Holman, F. Zicarelli, B. 
Demaurex, J. Seif, J. Holovsky, C. Ballif, Improved amorphous/crystalline silicon interface passivation by hydrogen plasma treatment, Appl. Phys. Lett. 99 (2011) 123506. https://doi.org/10.1063/1.3641899.

[9] H. Matsumura, H. Umemoto, A. Masuda, Cat-CVD (hot-wire CVD): how different from PECVD in preparing amorphous silicon, J. Non-Cryst. Solids 338 (2004) 19-26. https://doi.org/10.1016/j.jnoncrysol.2004.02.014.

[10] K. F. Feenstra, P. F. A. Alkemade, E. Algra, R. E. I. Schropp and W. F. van der Weg, Effect of post- deposition treatments on the hydrogenation of hot- wire deposited amorphous silicon films, Prog. in Photovoltaics: Research and Applications, 7 (1999) 341-351. https://doi.org/10.1002/(SICI)1099-159X(199909/10)7:5<341::AIDPIP261>3.0.CO;2-4

[11] K. Shimizu, N. Kohama, T. Tani, J. Hanna, Post hydrogenation effect by hot wire method on poly-crystalline silicon based devices, J. Non-Cryst. Solids, 338 (2004) 403-407. https://doi.org/10.1016/j.jnoncrysol.2004.03.007. [12] Zhi Qiao, Xinjian Xie, Qiuyan Hao, Di Wen, Junming Xue, Caichi Liu, Investigation of p-type nanocrystalline silicon emitters for silicon heterojunction solar cells, Appl. Sur. Sci. 324 (2015) 152-159. https://doi.org/10.1016/j.apsusc.2014.10.091.

[13] H. L. Duan, Stacey F. Bent, The influence of filament material on radical production in hot wire chemical vapor deposition of a-Si:H, Thin Solid Films 485 (2005) 126-134. https://doi.org/10.1016/j.tsf.2005.03.038.

[14] G. E. Jellison Jr., F. A. Modine, Parameterization of the optical functions of amorphous materials in the interband region, Appl. Phys. Lett. 69 (1996) 371-373. https://doi.org/10.1063/1.118064.

[15] A. H. M. Smets, W. M. M. Kessels, M. C. M. van de Sanden, Vacancies and voids in hydrogenated amorphous silicon, Appl. Phys. Lett. 82 (2003) 1547-1549. https://doi.org/10.1063/1.1559657.

[16] E. Bhattacharya, A. H. Mahan, Microstructure and the light- induced metastability in hydrogenated amorphous silicon, Appl. Phys. Lett. 52 (1988) 1587-1589. https://doi.org/10.1063/1.99089.

[17] K. K. Gleason, K. S. Wang, M. K. Chen, J. A. Reimer, Monte Carlo simulations of amorphous hydrogenated silicon thin- film growth, J. Appl. Phys. 61 (1987) 2866-2873. https://doi.org/10.1063/1.337882.

[18] A. Terakawa , H. Matsunami, Hydrogen elimination model of the formation of hydrogen bonding structures during the growth of hydrogenated amorphous silicon by plasma CVD, Phys. Rev. B 62 (2000) 16808 . https://doi.org/10.1103/PhysRevB.62.16808.

[19] Liping Zhang, Wanwu Guo, Wenzhu Liu, Jian Bao, Jinning Liu, Jianhua Shi, Fanying Meng, Zhengxin Liu, Investigation of positive roles of hydrogen plasma treatment for interface passivation based on silicon heterojunction solar cells, J. Phys. D: Appl. Phys. 49 (2016) 165305.

[20] A. Tomasi, F. Sahli, J. P. Seif, L. Fanni, S. M. d. N. Agut, J. Geissbu“hler, B. Paviet-Salomon, S. Nicolay, L. 
Barraud, B. Niesen, S. De Wolf, C. Ballif, Transparent electrodes in silicon heterojunction solar cells: Influence on contact passivation, IEEE J. Photovoltaics 6 (2016) 17-27. 10.1109/JPHOTOV.2015.2484962.

[21] B. Macco, J. Melskens, N. J. Podraza, K. Arts, C. Pugh, O. Thomas, W. M. M. Kessels, Correlating the silicon surface passivation to the nanostructure of low-temperature a-Si: H after rapid thermal annealing, J. Appl. Phys. 122 (2017) 035302. https://doi.org/10.1063/1.4994795.

[22] Shui-Yang Lien, Dong-Sing Wuu, Bing-Rui Wu, Ray-Hua Horng, Ming-Chun Tseng, Hsin-Her Yu, Hot-wire CVD deposited n-type $\mu \mathrm{c}-\mathrm{Si}$ films for $\mu \mathrm{c}-\mathrm{Si} / \mathrm{c}-\mathrm{Si}$ heterojunction solar cell applications, Thin Solid Films 516 (2008) 765-769. https://doi.org/10.1016/j.tsf.2007.06.054.

[23] G. Morell, R. S. Katiyar, S. Z. Weisz, H. Jia, J. Shinar, and I. Balberg, Raman study of the network disorder in sputtered and glow discharge a-Si:H films, J. Appl. Phys. 78 (1995) 5120. https://doi.org/10.1063/1.359743

[24] Z Iqbal and S Veprek, Raman scattering from hydrogenated microcrystalline and amorphous silicon, J. Phys. C: Solid State Phys. 15 (1982) 377-392.

[25] S. De Wolf and M. Kondo, Abruptness of a-Si:H/c-Si interface revealed by carrier lifetime measurements, Appl. Phys. Lett. 90 (2007) 042111. http://dx.doi.org/10.1063/1.2432297.

[26] Renfang Chen, Liping Zhang, Wenzhu Liu, Zhuopeng Wu, Fanying Meng, Zhengxin Liu, Optimized n-type amorphous silicon window layers via hydrogen dilution for silicon heterojunction solar cells by catalytic chemical vapor deposition, J. Appl. Phys. 122 (2017) 125110. https://doi.org/10.1063/1.5005511.

[27] Wenzhu Liu, Liping Zhang, Shiyuan Cong, Renfang Chen, Zhuopeng Wu, Fanying Meng, Qiang Shi, ZhengxinLiu, Controllable a-Si: H/c-Si interface passivation by residual $\mathrm{SiH}_{4}$ molecules in $\mathrm{H}_{2}$ plasma, Sol. Energy Mater. Sol. Cells 174 (2018) 233-239. https://doi.org/10.1016/j.solmat.2017.09.009.

[28] Z. C. Holman, A. Descoeudres, L. Barraud, F. Z. Fernandez, J. P. Seif, S. De Wolf, C. Ballif, Current losses at the front of silicon heterojunction solar cells, IEEE J. Photovoltaics 2 (2012) 7-15. 10.1109/JPHOTOV.2011.2174967. [29] Kaining Ding, U. Aeberhard, V. Smirnov, B. Holla“nder, F. Finger, U. Rau, Wide Gap Microcrystalline Silicon Oxide Emitter for a-SiOx:H/c-Si Heterojunction Solar Cells, Jpn. J. Appl. Phys. 52 (2013) 122304. http://dx.doi.org/10.7567/JJAP.52.122304. 